\title{
Role of non-descent vaginal hysterectomy in previous cesarean section scar women
}

\author{
Naina Kumar*, Surekha Tayade
}

Department of Obstetrics \& Gynecology, Mahatma Gandhi Institute of Medical Sciences, Sewagram Wardha-442102, Maharashtra, India

Received: 10 April 2015

Accepted: 05 May 2015

\section{*Correspondence:}

Dr. Naina Kumar,

E-mail: drnainakumar@gmail.com

Copyright: () the author(s), publisher and licensee Medip Academy. This is an open-access article distributed under the terms of the Creative Commons Attribution Non-Commercial License, which permits unrestricted non-commercial use, distribution, and reproduction in any medium, provided the original work is properly cited.

\begin{abstract}
Background: Non Descent Vaginal Hysterectomy (NDVH) is removal of uterus through vagina in absence of cervical descent. Objective: To assess safety, feasibility of NDVH in patients with previous cesarean section.

Methods: Prospective study was conducted at department of Obstetrics and Gynecology of rural Tertiary care centre of Central India from January 2013 to December 2014. Effort was made to perform hysterectomies vaginally in women with benign conditions in absence of prolapsed uterus with history of one, two or three cesarean sections. Women with adnexal masses, endometriosis/big uterus (>16 weeks) were excluded from study. Information regarding age, parity, uterine size, blood loss, duration of operation, difficulties in separating bladder, intra-operative, postoperative complications, hospital stay were recorded.

Results: Total ten cases were selected for NDVH with history of one, two/ three cesarean sections. All successfully underwent NDVH, except one in which bladder injury occurred which was repaired at same time from below. Five patients had previous one Lower Segment Cesarean Section (LSCS), four had two LSCS and one had three LSCS. Commonest indication was leiomyoma of uterus followed by abnormal uterine bleeding. Mean duration of surgery was $50 \pm 20.5 \mathrm{~min}$. Mean blood loss was $150 \pm 65 \mathrm{ml}$. Post-operative complications were minimal with no scar, patient mobility, resumption of daily activities was fast. Mean hospital stay was 4-5 days.

Conclusions: Vaginal hysterectomy appears to be safe, cost effective alternative to abdominal hysterectomy in women with previous cesarean section scar requiring hysterectomy for benign conditions with fewer complications, shorter hospital stay.
\end{abstract}

Keywords: Bladder, Cesarean section, Hysterectomy, Non descent vaginal hysterectomy

\section{INTRODUCTION}

Hysterectomy is commonly performed gynecological procedures. ${ }^{1} \mathrm{NDVH}$ is removal of uterus through vagina in absence of descent. Vaginal route is preferred for removing uteri, as it gives natural route, scarless, safer results than abdominal route. ${ }^{2}$ Because of increased cesarean sections, women undergoing hysterectomies with cesarean sections are increasing. ${ }^{3}$ Earlier previous cesarean section was relative contraindication to vaginal hysterectomy due to uterovesical adhesions and risk for unintended cystostomy. ${ }^{4-7}$ Skill, experience of surgeon is important in determining approach route. Study will help in assessing safety, feasibility of NDVH in women with previous cesarean section in absence of uterine prolapse.

\section{METHODS}

A prospective study was conducted at the department of Obstetrics and Gynecology of a rural Tertiary care centre of Central India from January 2013 to December 2014. A 
total of ten patients admitted to gynecological ward requiring hysterectomy for benign diseases in the absence of uterine prolapsed and with previous history of one, two or three cesarean sections, without suspected adnexal pathology were taken for study. All the criteria for NonDescent Vaginal Hysterectomy (NDVH) were fulfilled like uterine size not more than 16 weeks (by clinical judgment) with normal uterine mobility. Exclusion criteria included non-mobile uterus, any malignancy, adnexal masses. A proper written informed consent was taken from all patients after explaining the procedure and Special consent for conversion to abdominal hysterectomy if needed and chances of bladder injury was taken. Pre-operative investigations including complete blood counts, urine examination, blood grouping, fasting and post prandial blood sugar, serum creatinine, blood urea, endometrial biopsy, ECG, chest X-ray/USG whole abdomen and pelvis was done.

All cases were done under spinal or epidural anesthesia. In all cases a per vaginum examination was done under anesthesia before starting the surgery to again have an idea about size, mobility of uterus and any adnexal mass. After following all aseptic measures the patients were cleaned and drapped. The anterior lip of cervix was held with volsellum and posterior lip with long Allie's forceps. Circular incision was made around the cervix, pubo-vesico-cervical ligament was cut and bladder mobilized upwards. At the site of previous scar bladder was sharply dissected out and then carefully mobilized upwards by diver's speculum, till the anterior peritoneum covering the uterus is visible as glistening white, as shown in Figure 1 and 2. The anterior peritoneum is opened carefully by applying two artery forceps and cutting in between. Posterior pouch was opened subsequently. Uterosacral and cardinal ligaments were clamped, cut and ligated. Bilateral clamping of uterine vessels was done. After clamping and ligating uterine arteries on both sides, if the size of uterus was big then debulking techniques like bisection, decoring, myomectomy or a combination of these methods were done to facilitate vaginal delivery of uterus as shown in Figure 3, Figure 4. After delivering the uterus in the vagina, hysterectomy was completed by applying bilateral cornual clamps, cutting and ligating it properly. All the pedicles were rechecked for any bleeding or oozing and vault closed meticulously. Figure 5, 6 and 7 shows uterus with cervix and uterus with cervix with fibroid removed by myomectomy after completion of NDVH respectively. NDVH was considered successful if it was not abandoned or converted to laparotomy. Operating time was calculated from the start of incision at cervico-vaginal junction to packing of vagina. Estimation of blood loss was done by counting the number of Mops used during surgery and amount of blood in suction bottle. Foley's catheter was kept in all patients for 24 hours and all were given injectable antibiotics postoperatively for 48 hours. On postoperative day 2 , hemoglobin estimation was done in all patients. Any post-operative complications, if present were noted. All patients were asked to come for follow up after 15 days and 6 weeks of discharge. Information regarding age, parity, size of uterine, amount of blood loss, duration of operation, complications and hospital stay were recorded and statistically analyzed using SPSS software.

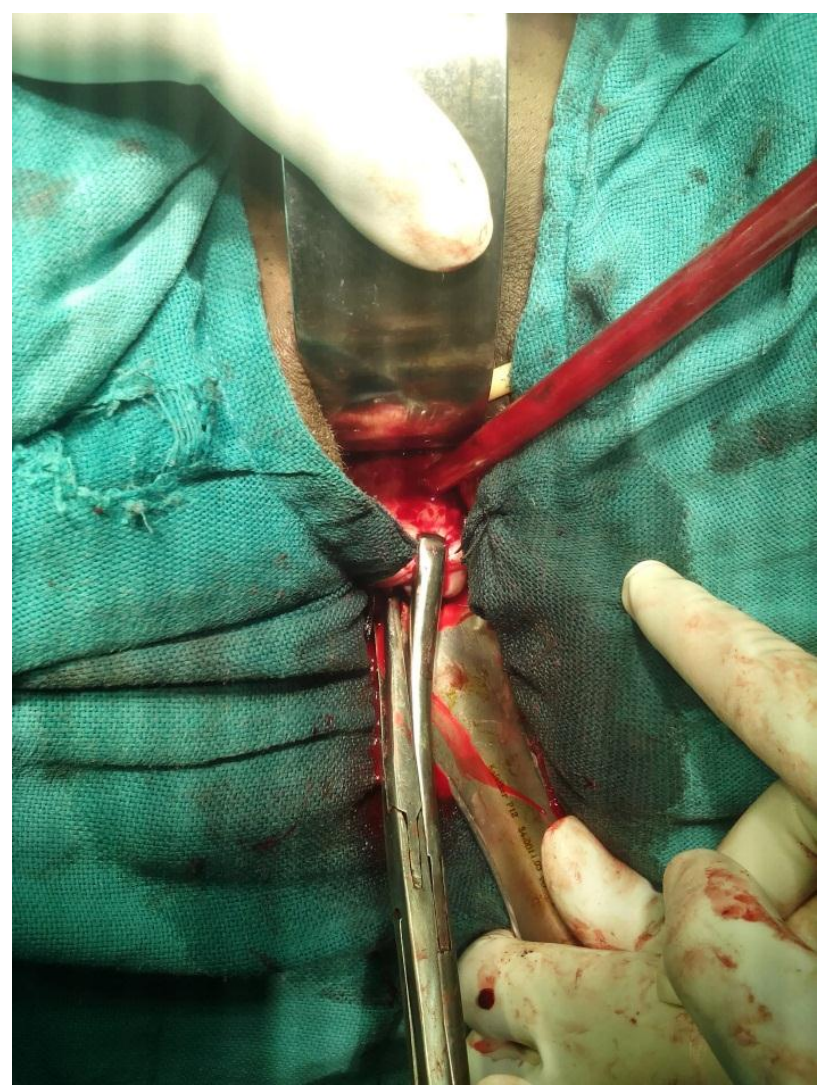

Figure 1: Shows site of previous cesarean scar.

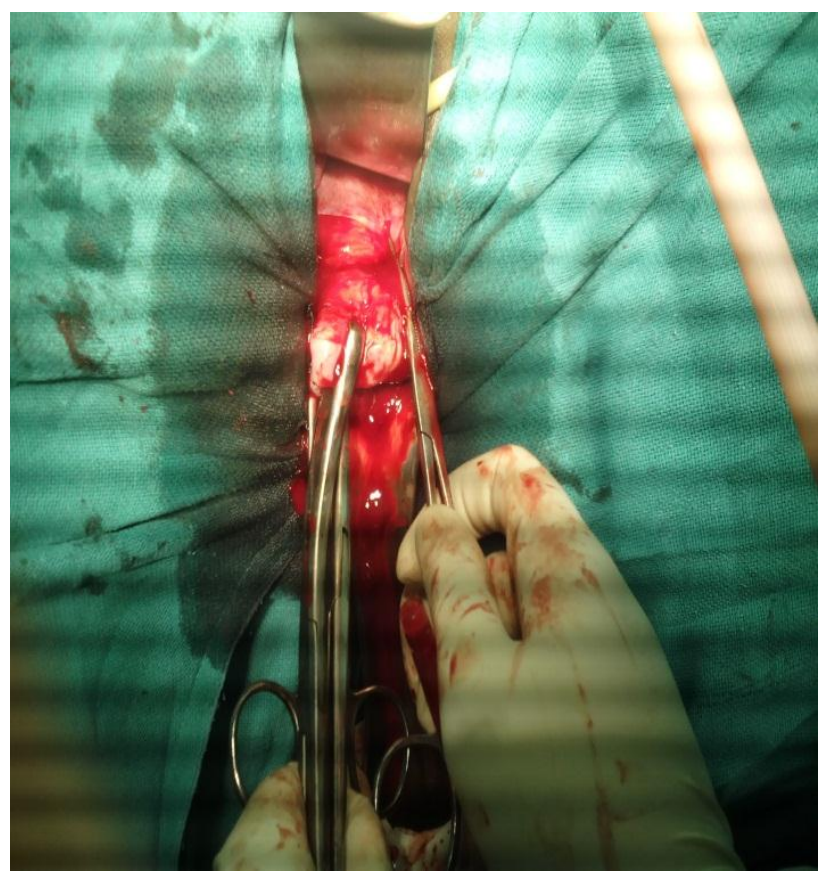

Figure 2: Shows anterior peritoneum to be opened. 


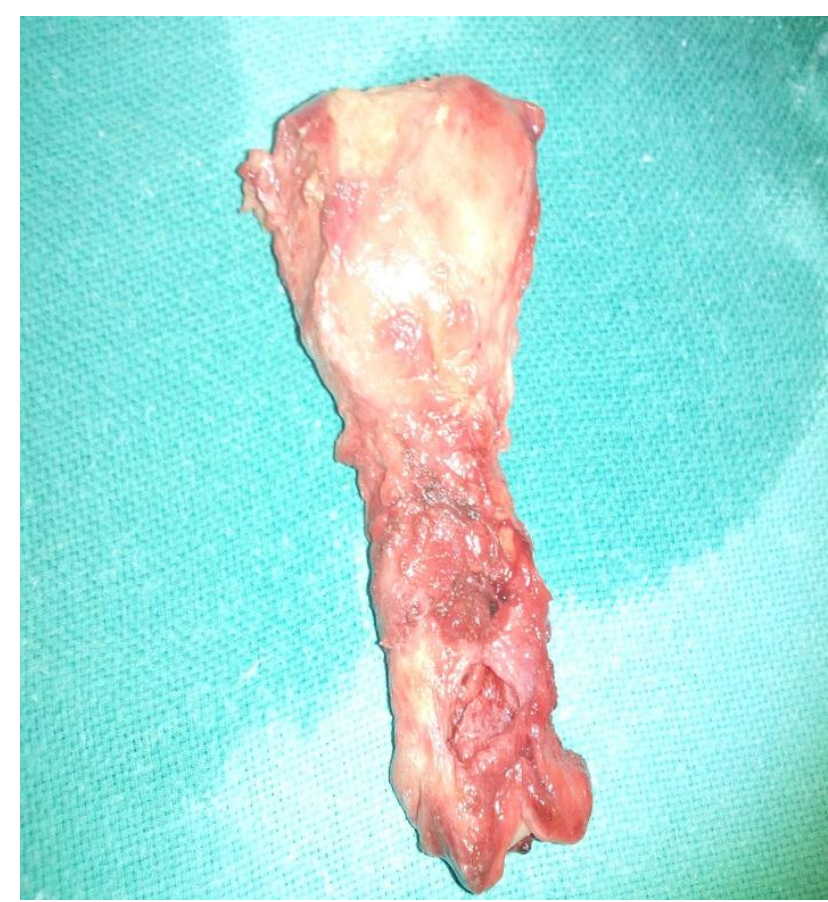

Figure 3: Shows uterus after hysterectomy without bilateral tubes and ovaries.

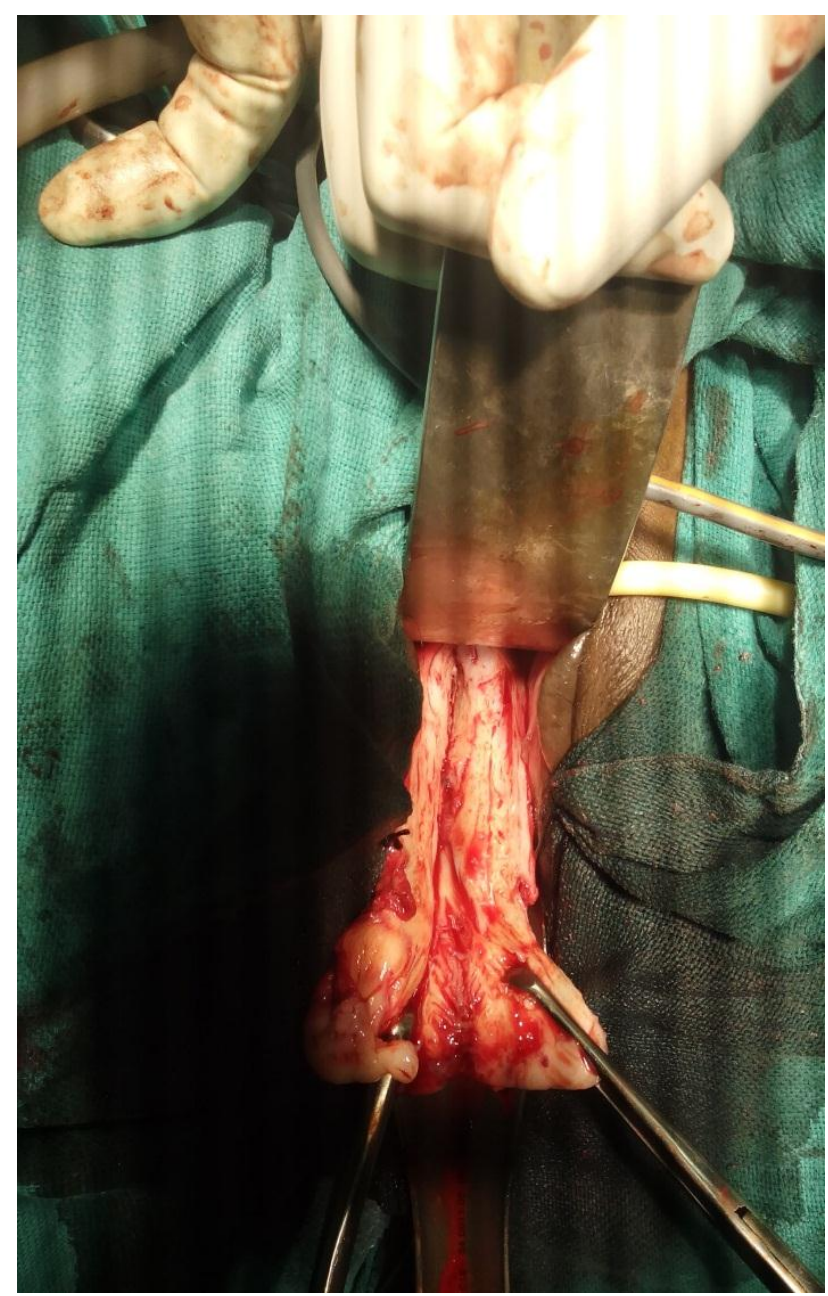

Figure 4: Shows bisected uterus for debulking.

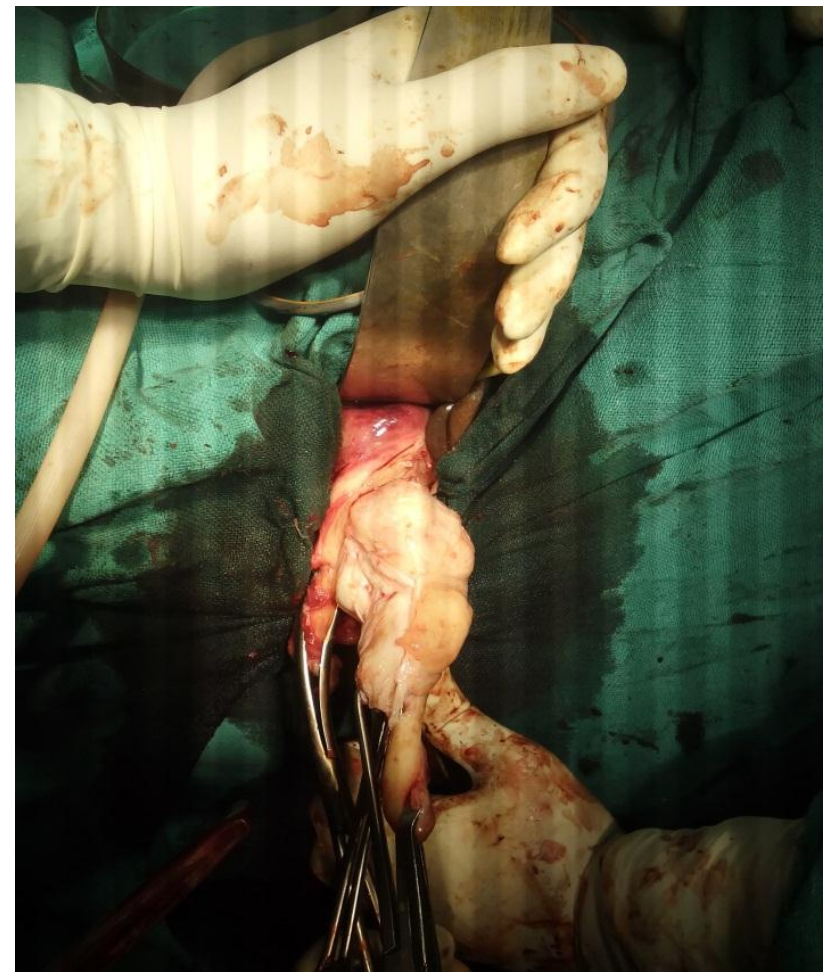

Figure 5: Shows uterus with fibroid and myomectomy is being done.

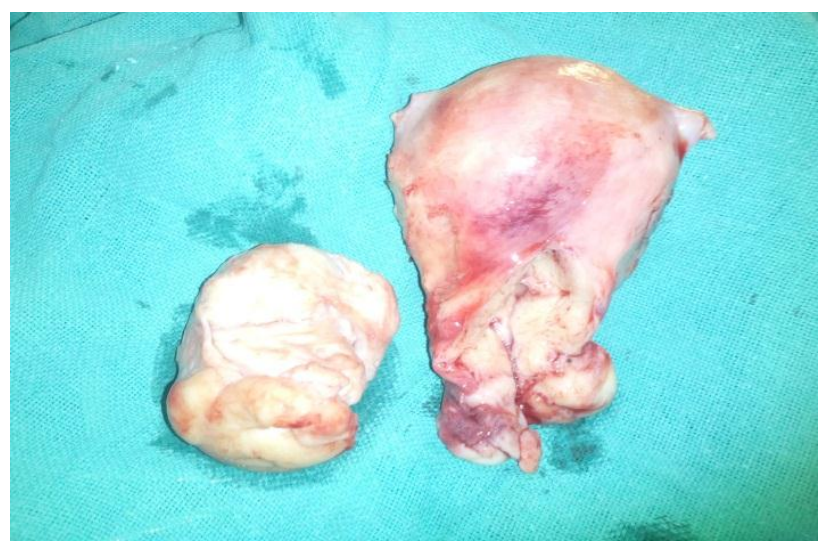

Figure 6: Shows uterus with fibroid after hysterectomy.

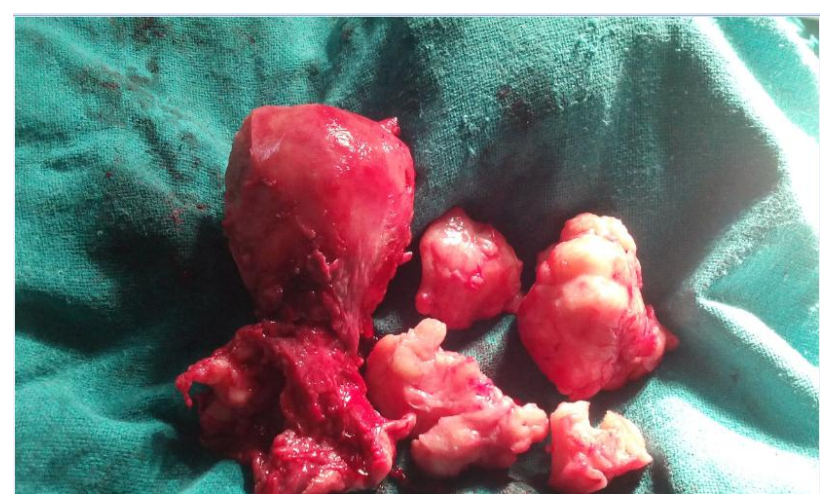

Figure 7: Shows uterus with multiple small fibroids removed with myomectomy. 


\section{RESULTS}

Among 10 women included in the study 9 women successfully underwent non-descent vaginal hysterectomy without any complications, whereas one case had bladder injury which was corrected from below only. All the women belonged to age group 40- 45 years. Table 1 depicts the Age wise distribution of women. Majority of women were para 2 and above. Five women had previous one LSCS, four had previous two LSCS and one had previous three LSCS. Parity wise and number of cesarean section wise distribution of patients is given in Table 2 and Table 3 respectively. The commonest indication for hysterectomy was fibroid uterus $4 / 10$ (40\%) followed by Abnormal uterine bleeding in 3/10 (30\%), Adenomyosis in $2 / 10(20 \%)$ and endometrial polyp in $1 / 10(10 \%)$. Table 4 depicts the distribution of women according to indication for surgery.

Table 1: Age wise distribution of patients.

\begin{tabular}{|lll|}
\hline $\begin{array}{l}\text { Age } \\
\text { (years) }\end{array}$ & $\begin{array}{l}\text { Number of } \\
\text { women }\end{array}$ & Percentage \\
\hline$>35-<40$ & 2 & $20 \%$ \\
\hline $40-<45$ & 7 & $70 \%$ \\
\hline $45-50$ & 1 & $10 \%$ \\
\hline
\end{tabular}

Table 2: Parity wise distribution of patients.

\begin{tabular}{|lll|}
\hline Parity & $\begin{array}{l}\text { Number of } \\
\text { women }\end{array}$ & Percentage \\
\hline Para 1 & 2 & $20 \%$ \\
\hline Para 2 & 6 & $60 \%$ \\
\hline Para3 & 1 & $10 \%$ \\
\hline Para 4 or more & 1 & $10 \%$ \\
\hline
\end{tabular}

Table 3: Number of previous cesarean section scars.

\begin{tabular}{|lll|}
\hline $\begin{array}{l}\text { No. of CS } \\
\text { scars }\end{array}$ & $\begin{array}{l}\text { Number of } \\
\text { women }\end{array}$ & Percentage \\
\hline 1 & 5 & $50 \%$ \\
\hline 2 & 4 & $40 \%$ \\
\hline 3 & 1 & $10 \%$ \\
\hline
\end{tabular}

Table 4: Indications for non-descent vaginal hysterectomy.

\begin{tabular}{|lll|}
\hline Indication & $\begin{array}{l}\text { Number of } \\
\text { women }\end{array}$ & Percentage \\
\hline Fibroid uterus & 4 & $40 \%$ \\
\hline Abnormal uterine bleeding & 3 & $30 \%$ \\
\hline Adenomyosis & 2 & $20 \%$ \\
\hline Endometrial polyp & 1 & $10 \%$ \\
\hline
\end{tabular}

Of 10 women, 3 had uterine size less than 12 weeks $3 / 10$ (30\%), 5 had uterine size more than 12 weeks but less than 14 weeks $5 / 10(50 \%), 2$ had uterine size between 14 16 weeks $2 / 10(20 \%)$ as depicted in Table 5. Different morcellation techniques like bisection, myomectomy and debulking techniques were used during the surgery to remove bigger sized Uterus. Debulking techniques were done in 4/10 (40\%) patients, as depicted in Table 6. In the present study the mean operating time was $50 \pm 20.5$ minutes. Mean blood loss was $150 \pm 65 \mathrm{ml}$. Blood transfusion was not needed in any patients. There was bladder injury in one patient intra-operatively who had previous 2 LSCS which was repaired from below only, without any need for laprotomy. Mean hospital stay was 4-5 days. Post-operative period was uneventful in all patients except for one which had bladder injury. In this case patient was kept catheterized for 14 days.

Table 5: Uterine size in selected cases for Non descent vaginal hysterectomy.

\begin{tabular}{|lll|}
\hline $\begin{array}{l}\text { Uterine size } \\
\text { (weeks) }\end{array}$ & Cases & Percentage \\
\hline $6-<12$ weeks & 3 & $30 \%$ \\
\hline $12-<14$ weeks & 5 & $50 \%$ \\
\hline $14-<16$ weeks & 2 & $20 \%$ \\
\hline
\end{tabular}

Table 6: Debulking techniques used for removal of big uterus.

\begin{tabular}{|ll|}
\hline Technique & Cases \\
\hline Bisection & 2 \\
\hline Myomectomy & 2 \\
\hline Morcellation (slicing and wedge debulking) & 1 \\
\hline
\end{tabular}

\section{DISCUSSION}

In absence of uterine prolapse, most gynecologists prefer abdominal to vaginal route of hysterectomy. The factors that may influence the route of hysterectomy for any surgical indication include uterine size, its mobility and pathology confined to the uterus with no adnexal masses. ${ }^{8}$ In the present study out of 10 cases selected for NDVH that had previous one, two or three cesarean section scars, all were completed successfully, except for one in which bladder injury occurred, but that too was corrected vaginally and the hysterectomy was completed vaginally only. The main reason of failure to perform NDVH in previous scar women is difficulty in separating the bladder at the previous scar site and opening of anterior peritoneum. Majority of the patients were in age group of 40-45 years and were parous as noted in other studies. ${ }^{9-13}$

A major factor in determining the route of hysterectomy is transvaginal accessibility of the uterus. ${ }^{14}$ Two factors limit accessibility, an undescended, immobile uterus and a vagina narrower than 2 fingerbreadths, especially at the apex. ${ }^{14}$ Determining whether the pathology is confined to or extends beyond the confines of the uterus is critical to selecting the most appropriate route of hysterectomy. The presence of severe endometriosis, adnexal pathology, adhesions because of previous pelvic surgeries contraindicate vaginal hysterectomy. ${ }^{14,15}$ The commonest indication was fibroid uterus $(40 \%)$. Fibroid uterus was also the commonest indication in other case series. ${ }^{10,11,13}$ 
Mean blood loss was $150 \pm 65 \mathrm{ml}$ and amount of loss depend on uterine size and duration of surgery. Similar results were reported by other studies also. ${ }^{12,16,17}$ Mean duration of surgery was $50 \pm 20.5$ minutes as compared to Dewan et al. (54.5 minutes), ${ }^{10}$ Bharatnur et al. (65 minutes), ${ }^{11}$ and Bhadra (55 minutes). ${ }^{12}$ The operative time was definitely more in the earlier phase of the learning curve and also dependent on the size of uterus and experience of the surgeon. ${ }^{14}$ Our study included ten cases with previous LSCS; Intra-operatively one case had bladder injury (1\%) that had previous two LSCS. Bladder injury during vaginal hysterectomy has been variously reported between 0.5 to $1.6 \% .^{14}$ A similar study reported an incidence of $2.8 \%$ in the past LSCS group vs. $1.6 \%$ in those without caesarean section. ${ }^{18}$ Another study reported a very low incidence of bladder injury $7 / 5655(0.1 \%){ }^{19}$ Post-operative complications were minimal. Mean hospital stay was 4-5 days. Hence non descent vaginal hysterectomy is safe, less invasive technique with benefits of shorter hospital stay and faster recovery. It is surgical method of choice for benign conditions of uterus and should be a primary method for removal of uterus, if not contraindicated.

\section{ACKNOWLEDGEMENTS}

I acknowledge and thank Dr. Namit Kant Singh for his advice and expertise.

\section{Funding: No funding sources}

Conflict of interest: None declared

Ethical approval: The study was approved by the institutional ethics committee

\section{REFERENCES}

1. Singh KC, Barman SD, Sengupta R. Choice of hysterectomy for benign disease, department of obstetrics and gynaecology, university college of medical sciences, Delhi. J Obstet Gynecol. 2004;54:365-70.

2. Unger JB. Vaginal hysterectomy for the women with moderately enlarged uterus weighing 200-700 grams. Am J Obstet Gynecol. 1999;180:1337-44.

3. Purohit RK, Sharma JG, Singh S, Giri DK. Vaginal hysterectomy by electrosurgery for benign indications associated with previous cesarean section. J Gynecol Surg. 2013;29(1):7-12.

4. Rooney CM, Crawford AT, Vassallo BJ. Is previous cesarean section a risk for incidental cystotomy at the time of hysterectomy? A case-controlled study. Am J Obstet Gynecol. 2005;193:2041.

5. Lafay Pillet MC, Leonard F, Chopin N. Incidence and risk factors of bladder injuries during laparoscopic hysterectomy indicated for benign uterine pathologies: a 14.5 year experience in a continuous series of 1501 procedures. Hum Reprod. 2009;24:842.
6. Wang L, Merkur H, Hardas G, Soo S, Lujic S. Laparoscopic hysterectomy in the presence of previous caesarean section: a review of one hundred forty-one cases in the Sydney West Advanced Pelvic Surgery Unit. J Minim Invasive Gynecol. 2010;17:186.

7. Mathevet $P$, Valencia $P$, Cousin C, Mellier G, Dargent D. Operative injuries during vaginal hysterectomy. Eur J Obstet Gynecol Reprod Biol. 2001;97:71.

8. Kovac SR, Barhan S, Lister M, Tucker L, Bishop M, Das A. Guidelines for the selection of the route of hysterectomy: application in a resident clinic population. Am J Obstet Gynecol. 2002 Dec;187(6):1521-7.

9. Saha R, Shrestha NS, Thapa M, Shrestha J, Bajracharya J, Padhye SM. Non-descent vaginal hysterectomy: safety and feasibility. N J Obstet Gynecol. 2012;7(2):14-6.

10. Dewan R, Agarwal S, Minocha B, Sen SK. Nondescent vaginal hysterectomy - an experience. J Obstet Gynecol India. 2004;54(4):376-8.

11. Bharatnur S. Comparative study of abdominal versus vaginal hysterectomy in Non-Descent cases. Internet J Gynaecol Obstet. 2011;15(2):1528-39.

12. Bhadra B, Choudary AP, Tolassaria A, Nupur N. Non-descent vaginal hysterectomy (NDVH): personal experiences in 158 cases. AL Ameen J Med Sci. 2011;4(1):23-7.

13. Singh A, Bansal S. Comparative study of morbidity and mortality associated with non- descent vaginal hysterectomy based on ultra sonographic determination of uterine volume. Int Surg. 2008;93(2):88-94.

14. Chandana C, Venkatesh S, Shah TN. Non-descent vaginal hysterectomy for benign gynaecological disease - a prospective study. J Evidence Based Med Healthcare. 2014;1(8):827-33.

15. ACOG Educational Bulletin. Operative laparoscopy. Number 239, August 1997. American College of Obstetricians and Gynecologists. Int J Gynaecol Obstet. 1997 Dec;59(3):265-8.

16. Patel R, Chakravarty N. Comparative study of laparoscopic hysterectomy versus vaginal hysterectomy. Int $\mathrm{J}$ Med Sci Public Health. 2014;3:335-7.

17. Virmani S. Surgical trends in hysterectomy - a comparative analysis. Indian J Appl Res. 2014;12(4):261-3.

18. Unger JB, Meeks GR. Vaginal hysterectomy in women with history of previous cesarean delivery. Am J Obstet Gynecol. 1998 Dec;179(6 Pt 1):1473-8.

19. Sheth SS, Malpani AN. Vaginal hysterectomy following previous cesarean section. Int J Gynaecol Obstet. 1995 Aug;50(2):165-9.

DOI: $10.18203 / 2320-1770.1 j \mathrm{rcog} 20150092$

Cite this article as: Kumar N, Tayade S. Role of nondescent vaginal hysterectomy in previous cesarean section scar women. Int J Reprod Contracept Obstet Gynecol 2015;4:785-9. 